\title{
Mulheres intelectuais, cultura e educação no Brasil: notas de apresentação de um tema
}

EVELYN DE ALMEIDA ORLANDO

A proposta deste dossiê nasceu da lacuna identificada em um balanço realizado nas quatro revistas de História da Educação existentes no Brasil e nos anais do principal congresso da área - Congresso Brasileiro de História da Educação/CBHE - acerca desta temática. Do conjunto de trabalhos catalogados que enfocam as mulheres como sujeitos históricos, considerando sua presença, seus processos de formação e modos de participação na produção e mediação de saberes culturais, e atentando para a multiplicidade de práticas educativas que exerceram, poucos lançam luz para sua condição de intelectual. Essa lacuna é identificada em duas instâncias: nos trabalhos sobre mulheres elas raramente figuram como intelectuais e os trabalhos sobre intelectuais raramente versam sobre mulheres ${ }^{1}$.

Além disso, é importante observar que nos estudos biográficos do campo há uma recorrência à seleção de personagens que conduziram suas trajetórias a partir de pautas mais progressistas, participando de uma agenda política que visava à transformação da sociedade em diferentes momentos históricos. Mulheres que participavam de uma agenda mais conservadora pouco têm sido consideradas na historiografia. O critério de seleção, que parece orientar essas escolhas a partir do envolvimento do sujeito com uma agenda mais conservadora ou progressista, no entanto, não se aplica aos homens, haja vista termos estudos biográficos e de trajetórias de figuras como D. Leme, Jackson de Figueiredo, Jonatas Serrano e tantos outros intelectuais que participaram ativamente do

\footnotetext{
a Pontifícia Universidade Católica do Paraná

${ }^{1}$ Cf. o trabalho de iniciação científica de Suzane Tizott, desenvolvido entre 2018-2019, na PUCPR.

Rev. Caminhos da Educação: diálogos, culturas e diversidades, Teresina, v. 2, n. 3, p. 3-9, set./dez. 2020
} 
projeto católico conservador de salvação nacional que se materializou no Centro D. Vital e na revista $A$ Ordem, por exemplo. O que temos perdido com esse recorte?

No caso francês, por exemplo, é digno de nota que a afirmação dos intelectuais católicos como grupo, cinquenta anos após o caso Dreyfus, deve-se à Madeleine Leroy, religiosa da congregação das Filhas do coração de Maria, que fundou o Centre catholique des intellectuels français, instituição que legitimou a expressão intelectuais católicos. Tal iniciativa é indicativa da participação política das mulheres no campo intelectual, tal como estudaram, sob enfoques diferenciados, Guyot (2001) e Rochefort (2001). No entanto, assim como no Brasil, esse tipo de abordagem parece ser também um ponto fora da curva na historiografia francesa com a qual a História da Educação no Brasil dialoga de forma muito estreita.

Segundo Perrot (1995, p. 20, 21), a História das Mulheres na França levou vinte anos para se consolidar como campo de pesquisa e seguiu uma sistemática na produção: em um primeiro momento se voltou para "figuras femininas mais oprimidas", tais como prostitutas, domésticas, mulheres agredidas, etc; em um segundo momento, voltou-se para questões relacionadas ao corpo da mulher; e, em um terceiro momento, voltou-se para as mulheres como "agentes responsáveis pelos seus destinos individuais e coletivos, sobre suas capacidades de resistência e de transformação".

No Brasil, a História da Educação tem se proposto já desde meados dos anos de 1980 a olhar seus objetos, a partir de questões que evidenciam o processo histórico, a partir de projetos em disputa e dos diferentes sujeitos e instituições envolvidos nessas configurações, mas ainda temos deixado escapar a participação política das mulheres nessa história, sobretudo as conservadoras, possivelmente pela aproximação da historiografia francesa, cujos recortes nesse período estavam voltados para pautas do movimento feminista.

Deste modo, se existe uma lacuna em relação às mulheres intelectuais em nossa historiografia educacional, esta é ainda maior existe em relação às intelectuais conservadoras. Sobre estas, os modos de atuação, os saberes que produziram e colocaram em circulação e a forma como se inseriram no campo 
da produção intelectual e cultural do país, seus modos de engajamento em projetos conservadores, têm nos escapado.

Pensar as mulheres como intelectuais passa por considerar para além da definição do conceito - o que fazemos a partir de Sirinelli (1996), considerandoas como produtoras e mediadoras culturais e atrizes do político -, seus modos de intervenção política. Nesse sentido, valemos-nos da definição proposta por Gisèle Sapiro sobre os oito modelos de intervenção, construídos a partir do caso francês e de maneira ideal-típica, a saber: o intelectual crítico universalista, o intelectual crítico especializado, o guardião da ordem moralizador, o especialista consultado pelos dirigentes, grupos contestadores universalistas, grupos contestadores especializados, o intelectual de instituição generalista e o intelectual de instituição especializado. Esses modelos tendem a se diferenciar conforme três fatores que, segundo a autora, estruturam o campo intelectual: o capital simbólico; a autonomia em relação à demanda política; e o grau de especialização. (SAPIRO, 2012)

Deste modo, se a opção pelas mulheres como intelectuais parece estar relacionada, em primeiro plano, à tentativa de contribuir com a História das Mulheres, o objetivo maior vai um pouco além, qual seja o de pensar uma História Intelectual e dos intelectuais com a participação das mulheres. No entanto, a reivindicação desse lugar passa, por vezes, por inscrever as mulheres na História a partir de suas próprias histórias, considerando seus diferentes perfis, projetos e modos de engajamento.

Atentar para as formas como viveram, tanto em suas experiências privadas quanto públicas, entender suas ações, suas escolhas, seus caminhos, longe de ter um sentido laudatório, tem um sentido de compreender a história em suas diferentes nuances, por diferentes lentes, evitando o perigo da história única, produzida pelos grupos que controlam a narrativa pelo lugar de poder que ocupam, sendo, em larga medida, homens, ocidentais, brancos, de classe social privilegiada. Nesse sentido, a História das Mulheres é imbuída também de um sentido político de reivindicação pelo reconhecimento dos sujeitos e suas histórias, de afirmação de suas existências e identidades, sejam elas quais forem. Nesse sentido, 
inscrever as mulheres na história implica necessariamente a redefinição e o alargamento das noções tradicionais do que é historicamente importante, para incluir tanto a experiência pessoal e subjetiva quanto as atividades públicas e políticas. Não é exagerado dizer que por mais hesitante que sejam os princípios reais de hoje, tal metodologia implica não só em uma nova história das mulheres, mas em uma nova história. (GORDON, BUHLE \& DYEAPUD apud SCOTT, 1995, p. 3,4)

Qual a grande provocação para pensarmos a História das Mulheres de maneira não separatista da história? Se por um lado as mulheres possuem uma história própria, de outro, seu reconhecimento na História, só vai acontecer quando ela aparecer imiscuída aos acontecimentos, aos problemas, à dinâmica do processo histórico.

O desafio lançado por este tipo de reações é, em última análise, um desafio teórico. Ele exige a análise não só da relação entre experiências masculinas e femininas no passado, mas também a ligação entre a história do passado e as práticas históricas atuais. Como é que o gênero funciona nas relações sociais humanas? Como é que o gênero dá um sentido à organização e à percepção do conhecimento histórico? As respostas dependem do gênero como categoria de análise. (SCOTT, 1995, p. 5)

Pensar as mulheres nesse bojo é pensar, portanto, de modo relacional. E, nessa relação, marcar as suas especificidades e discutir como, a partir desse modo de ser e agir, as mulheres intervieram no processo histórico, como suas ações no bojo dos acontecimentos dão mostras do modo como as relações humanas se estruturam, como elas tiveram que criar regras próprias para se inserirem nos jogos de poder, o que essas táticas como demarcação de um espaço significam em termos práticos, de que forma sua participação no âmbito da política, da cultura e da educação impactou a sociedade?

No âmbito da educação, podemos pensar sobre suas práticas, nas disputas políticas em que se envolveu, para ocupar determinados espaços. Que marcas deixou? Que discursos produziu? Que valores, comportamentos e saberes difundiu? De que modo suas práticas reverberaram na produção da cultura e nas formas de organização da sociedade? Como suas ações foram orientadas pela condição de gênero e em que medidas elas contribuíram para Rev. Caminhos da Educação: diálogos, culturas e diversidades, Teresina, v. 2, n. 3, p. 3-9, set./dez. 2020 
reproduzir ou romper determinadas representações relacionadas a essa condição?

Pensar as mulheres como intelectuais não pode prescindir da categoria de gênero porque essa é uma das balizas que orienta suas ações no campo intelectual. Todavia, não basta pensar o que é ser intelectual no feminino. É preciso pensar como esse feminino se constitui como sujeito no campo intelectual e como as mulheres se configuram como intelectuais em relação aos homens no interior do campo, as disputas travadas não apenas com os homens, mas também entre si, as negociações tácitas que empreendem uma vez que estão fora do território que Ihes é prescrito, e os micropoderes que exercem a partir daí.

Falamos de mulheres para compreender como sua condição sexual e o simbolismo dessa condição marcaram seus lugares de fala e ação na sociedade brasileira, assim como seu reconhecimento no próprio campo intelectual e científico porque, em larga medida, ao falarmos de intelectuais, nosso pensamento tende a trazer à memória uma figura masculina.

Os trabalhos reunidos neste dossiê abordam quatro mulheres com perfis distintas que, por caminhos diversos, imprimiram marcas na produção intelectual e cultural de seu tempo. A partir de áreas distintas - Teologia, Educação, Artes e Letras - elas evidenciam o protagonismo que as mulheres assumiram nos projetos de organização da nação pela educação e pela cultura, pondo em relevo os múltiplos caminhos trilhados e as diversas práticas empreendidas nessa direção.

Santa Emilie de Villeneuve, fundadora da Congregação das Irmãs Azuis, oriunda de uma família da nobreza francesa ainda no início do século XIX, elaborou o Regulamento e as Constituições da Congregação fundada por ela e deixou um conjunto expressivo de cartas endereçadas à missionárias na África. Essa produção é indicativa de sua participação no campo teológico em assuntos concernentes às questões internas da Igreja.

Maria Junqueira Schmidt, intelectual e militante católica, se engajou em diferentes projetos voltados para a reconfiguração do campo educacional brasileiro, se apropriando das contribuições das ciências da educação e introduzindo-as na pedagogia católica. Sua atuação em prol da Igreja e da Rev. Caminhos da Educação: diálogos, culturas e diversidades, Teresina, v. 2, n. 3, p. 3-9, set./dez. 2020 
Educação permite situá-la como uma forte representante do que se tem chamado de escolanovismo católico.

As mulheres artistas da geração de 80 em Curitiba, por sua vez, dão a ver caminhos de sua circulação e representatividade no sistema de artes em Curitiba/PR. É indicativo das estratégias de permanência no campo da arte de um grupo de mulheres que ingressam no mercado simbólico na década de 1980 e conservam posições de vanguarda no início dos anos 2000. Tais mulheres situam-me como intermediárias culturais ao atuarem como professoras, gestoras ou curadoras no campo artístico, educacional ou cultural paranaense.

Carmen Dolores, pseudônimo de Emília Moncorvo Bandeira de Mello (1852-1910), foi uma escritora e intelectual de grande prestígio no mundo das letras do Rio de Janeiro e do país, na virada do século XIX para o XX. Autora de obras de gêneros diversos, notabilizou-se por seu talento como cronista, que desenvolveu em diversos veículos da imprensa de então, demarcando seu lugar como uma mulher de letras, cujo trabalho assumiu também uma importante dimensão educativa alinhada com muitas das pautas do movimento feminista.

As personagens aqui reunidas são representativas das diferentes formas como as mulheres participaram da produção intelectual e cultural de seu tempo. Suas marcas produziram efeitos que podemos sentir nos dias atuais e que nos provocam a pensar onde estão as mulheres em nossa história intelectual?

Esse dossiê é um convite e uma provocação para buscarmos, nesse jogo de luzes e sombras que determina a narrativa historiográfica, outros atores e atrizes que participaram ativamente de sua época e cujos nomes, especialmente quando se trata de mulheres, são apagados da memória e da história.

\section{Referências Bibliográficas}

GUYOT, Claire, De l'engagement au désenchantement (1945-1975) ? Jalons pour une histoire des intellectuelles catholiques. Clio. Histoire, femmes et sociétés [En ligne], 13 | 2001, p. 1-9, mis en ligne le 19. juin 2006. Disponível em http://journals.openedition.org/clio/140. Acesso em 18 de abril de 2020. 
PERROT, Michelle. Escrever uma História das Mulheres: relatos de uma experiência, Cadernos Pagu (4), Dossiê: História das Mulheres no Ocidente, 1995, p. 9-28.

ROCHEFORT, Florance. À la découverte des intellectuelles. Clio. Histoire, femmes et sociétés [En ligne], 13 | 2001, mis en ligne le 10 novembre 2006. Dispnível em : http://journals.openedition.org/clio/131. Acesso: 18 de abril e 2020.

SAPIRO, Gisèle. Modelos de intervenção política dos intelectuais: o caso francês. R. Pós Ci. Soc. v.9, n.17, jan/jun. 2012, p. 19-50.

SCOTT, Joan. Gênero: uma categoria útil de análise. Educação \& Realidade, 20 (2), jul-dez, 1995, p. 71-99.

SIRINIELLI, Jean-François. Os intelectuais. RÉMOND, René. Por uma História política. $2^{\mathrm{a}}$ Tradução Dora Rocha. Ed. Rio de Janeiro: FGV, 2003, p. 231-270. TIZOTT, Suzane. Mulheres intelectuais, educação, religião e cultura: um balanço da produção no campo da História da Educação. Relatório Final de Iniciação Científica. Curitiba: PUCPR, 2019.

RECEBIDO: 01/08/2020

APROVADO: 10/09/ 2020
RECEIVED: $01 / 08 / 2020$

APPROVED: $10 / 09 / 2020$
RECIBIDO: 01/08/ 2020

APROBADO: $10 / 09 / 2020$ 